\title{
AFTER BREXIT: THE CHALLENGES OF HIGHER EDUCATION IN EUROPE AND LATIN AMERICA
}

\author{
Fernando G alván 1 \\ University of Alcalá \\ Madrid/Spain \\ rector@uah.es
}

\begin{abstract}
A bstract
This paper presents a discussion of the main issues involved in the Brexit decision and negotiations for Higher Education, Science, Technology and Innovation both for the EU and the UK. It analyses the challenges posed by the results of the British referendum in 2016, providing current data and figures about students, faculty, research and funding and how it might affect the future relations between the EU countries and the UK after 2019. In view of the new avenues opened after Brexit for higher education, research and innovation in the $\mathrm{UK}$ and the EU, it also addresses the current conditions and challenges of cooperation between Europe and Latin America and the Caribbean. The author, who is President of a birregional academic initiative, the Academic Permanent Forum for Latin America, Caribbean and the European Union (FAP ALC-UE), offers a summary of the main steps taken by this organization since 2012, which have led to the presentation of proposals to the political summits of Heads of State and Government of CELAC and the EU in Santiago de Chile (2013) and Brussels (2015). This is a grass-root movement constituted by members of universities and research centres in both regions whose main purpose is to put
\end{abstract}

${ }^{1}$ Fernando Galván is Rector of the University of Alcalá (Madrid, Spain) and President of the Academic Permanent Forum for Latin America, Caribbean and European Union (FAP ALC-UE) 
forward proposals for the establishment of a Common Birregional Area for Higher Education, Science, Technology and Innovation.

\section{Keywords}

Europe, Higher Education, Latin America,

One of the key issues in Europe at present, with larger implications globally, is the decision adopted in the referendum on 23rd June 2016 by the United Kingdom to leave the European Union, generally known as "Brexit", a decision taken by $51.9 \%$ of votes in favour of leaving, with $48.1 \%$ voting in favour of remaining. Even though the decision was taken more than a year ago, with a high $71.8 \%$ of turnout, and more than 30 million people voting, for months later the debate has gone on about what the real implications of the referendum would be like, and whether that result might be amended by Parliament or another referendum on the same subject.

But now the situation is particularly delicate after the British Government sent notification to the European Union on 29th March 2017 to withdraw under Article 50 of the Treaty on European Union. As is well known, a snap general election was called by Prime Minister Theresa May for 8th June 2017, with the purpose of gaining a clear majority in Parliament which would eventually give her more strength to implement the decision adopted in the referendum. The results of the election however were not those expected by PM May, so that the relations between $\mathrm{UK}$ and the EU at the time this paper is going to press (November 2017) are very uncertain. I wish to deal here only with some of the implications of the Brexit in the area of higher education, research, science, technology and innovation, and not only in the UK but in Europe at large, and the world globally.

The preoccupation among higher education institutions in the UK and Europe is obvious. Our colleagues in higher education across Europe, and even beyond Europe, have shared that concern in the previous months. I cannot mention in this paper all the aspects involved, but let me at least draw the reader's attention upon an interesting document issued by the House of Commons Education 
Committee, entitled Exiting the EU: Challenges and Opportunities for Higher Education, which is the ninth report of session 2016-17 of that Committee, published on 25th April 2017, which contains relevant information and data, as well as recommendations for the negotiation process of the British withdrawal from the EU. I do not wish to forget either the campaign launched by young people in the UK entitled "Undivided", which is also a good evidence of the interest among our youth in their future and the future of coming generations.

The British Council also launched this year a campaign in Europe in order to discuss this situation engaging British and European partners, an initiative known as "the British Council EU-UK Culture and Education Series"; two meetings took place, one in Berlin, on 15th-16th February; and the other in Madrid, on 24th-25th April. The reports of those two meetings are testament to the common concerns in the UK and EU about higher education, research, science and culture, about mobility of students and staff, about an open labour market for researchers, the need to consider this during the Brexit negotiations as a sort of excéption culturelle to be applied to higher education, culture, research and innovation, the perspectives about future funding for research, the immigration issue when applied to scholars, etc.

Students are a major preoccupation for all of us. According to that House of Commons report, in the previous academic year, 2015-16, there were 2.28 million students at UK universities; $5.6 \%$ of those students were from the EU, and $13.6 \%$ from non-EU countries (House of Commons Education Committee 2017, 8), i.e. almost $20 \%$ of the higher education population of the UK come from abroad, nearly 450,000 students. Hard measures against the entry in the UK of those students in the future might affect very negatively the quality and viability of many British universities, so all parties concerned are now asking the Government (I quote from that parliamentary report) to "guarantee home rate fees and access to tuition fee loans for EU undergraduate students starting in England in the academic year 2018/19 well in advance of the early deadline for course applications. The status of postgraduate students should also be clarified" (House of Commons Education Committee 2017, 10). If the Erasmus + programme cannot be applied or is substantially weakened, due to the withdrawal of funding by Britain, many thousands of students from the EU would have no access to free tuition fees at 
British universities through the current MoUs and exchange agreements, but also, of course, several thousands of British students would not be able to pursue their studies in EU countries.

In the academic year 2013/14 the outgoing student mobility from the UK via Erasmus was 15,610, a figure that has been increasing year by year in recent times. The same applies to academic staff. British students will be affected particularly in the fields of Clinical Medicine, French Studies, Spanish Studies, Business Studies and Other European Languages and Studies (Universities UK and UK HE International Unit 2016, 16-17), which means they will not have the opportunity to get the global training and competencies demanded by the labour market.

Moreover, foreign students are an important contribution to UK economy. According to data compiled by Universities UK, non-UK students generate an estimated 11 billion pounds for the economy. EU students alone "contributed 3.7 billion pounds for the UK economy and supported over 34,000 jobs in all corners of the country" (Universities UK and UK HE International Unit 2016, 28). The region most affected if those EU students don't have access to the UK universities would be London, because London receives 2,500 million pounds from non-UK students, and a large proportion of those are EU students.

But the preoccupation is not only related to students and future graduates, but is also addressed to teaching and scientific staff. The mobility of UK teachers and researchers will be seriously impeded, if EU professionals at the same level will not be allowed free movement in the UK. That would be a very serious blow to UK research. According to figures and statistics provided by Universities UK, in the year $201246.3 \%$ of UK research publications involved an international collaboration, i.e. were internationally co-authored, and "since 2003 the rate has grown faster than its key competitors except the USA, where only $30 \%$ of publications are internationally co-authored" (Universities UK and UK HE International Unit $2016,21)$. Data show that the world average for that year (2012) was $18 \%$ of coauthored papers (the UK had 46.3\%) and the growth rate between 2003-2012 was $8 \%$ (the UK's was $29.5 \%$ ).

Many of those international collaborations come precisely from EU countries. According to the same source (Universities UK and UK HE International 2016, 
$20)$, in the period 2008-2012 the UK's top 10 collaboration partners, by number of co-authored papers, are: 1) United States (89,579); 2) Germany $(45,250) ; 3)$ France $(33,454) ; 4)$ Italy $(27,789) ; 5)$ Australia $(24,403) ; 6)$ Netherlands $(24,147) ; 7)$ Spain $(23,258) ; 8)$ China $(22,813) ; 9)$ Canada $(21,860)$; and 10) Switzerland $(16,589)$. If we consider not the top 10, but the top 20 partner countries, the result is that 13 of those 20 countries are EU member states.

These figures can easily explain the turmoil that thousands of researchers and scientists, in all fields of knowledge, are now going through in the UK, but also in the EU. Although money is not all, it is certainly an essential component for the development and innovation of universities. Let us see only a few more details. As of April 2016, the projects coordinated by the UK under the EU Horizon 2020 programme were close to 1,500, the largest figure of all EU countries, being followed by Spain, with about 900, and Germany slightly lower (Universities UK and UK HE International Unit 2016, 26). Contrary to the Brexiters' message and complaint about the UK money which goes to fund the $\mathrm{EU}$, and according to the British parliamentary report mentioned earlier, "from 2007 to 2013, the UK contributed €5.4 billion to the EU for research, development and innovation; over the same time, the UK received $€ 8.8$ billion [more than 3 billion more than its contribution to EU funding]. $€ 6.9$ billion out of the $€ 8.8$ billion received was from Horizon 2020's predecessor, the Framew ork 7 Programme. UK universities were the most successful recipients of Framew ork 7 with a 71\% share" (House of Commons Education Committee 2017, 18).

The gross domestic expenditure on research and development funded from abroad in 2014 was nearly 19\% [18.9\%] in the UK, the largest percentage by far from all other countries in the world: Austria had 15\%; the Netherlands $12.5 \%$; Canada 6\%; Germany 5\%; the US 4.5\%; South Korea 0.7\%; and Japan $0.4 \%$ (Universities UK and UK HE International Unit 2016, 27). It is not difficult to imagine the strong preoccupation among British researchers and institutions if that international funding -a large part of which comes from the EU- will no longer go to the UK in the near future, after 2019, when the final withdrawal from the EU takes place.

Data also show that the area of the world which sends fewer students to the UK is South America. UK universities receive nearly 450,000 foreign students every 
year. Most of them come from the EU, China, India and other countries in Asia; also substantial numbers of students come from Africa, the Middle East and North America. Curiously enough, only slightly more than 2,000 students from South America go to UK universities, which is just $0.5 \%$ of the total number of foreign students at UK universities. (Universities UK and UK HE International Unit 2016, 14)

I believe that even if the EU and the UK reach a good agreement for the period after 2019, even if the UK manages to keep the high population of Asian and African students (which now seems a difficult issue, because international students would probably be part of the net migration target, if a hard Brexit takes place, according to the British Government policies in this sector), what remains a subject worthy of further exploration is South America, or Latin America and the Caribbean at large.

Paradoxically, the population of South America, according to 2015 statistics, is over 400 million people. If the Caribbean, Central America and Mexico are added, the figure will obviously increase to over 550 million or close to 600 million people. Even if the number of Latin American students who come to some European countries, like Spain, Portugal, France, Germany and Italy, is higher than that which goes to the UK, it is evident that there is still a lack of mobility in higher education and research between both regions. This is precisely an area in which the negative effects of Brexit both in the UK and in the EU could be counterbalanced if the educational, scientific and cultural relations between Latin America and Europe were stronger.

In my capacity as President of the Academic Permanent Forum for Latin America, Caribbean and European Union I would like to now focus on this field, which I consider to be a sort of wishing-well of opportunities and positive expectations if we know how to address the main issues of cooperation in higher education between the two regions. Let me thus provide in the following pages some information, reflections and thoughts about what we have been doing in the last five or six years and what we can modestly contribute, as an academic movement, to the progress of higher education in the two regions.

It is self-evident that the strategic association between the European region and the Latin American and Caribbean region must be based on firm academic 
grounds. For the preservation and fostering of peace, freedom, democracy, human rights and culture in its diverse manifestations, the direct involvement of the academic world is necessary, essential, because education is the basis for the advancement of knowledge, the creation of science, technology and innovation. Issues closely connected to those are of course economic progress, sustainable development, the reduction of the social gap and gender equality.

Thus a movement has been growing in numerous international conferences in Europe and America, for more than fifteen years now, in favour of the constitution of a forum which would allow for the exchange of experiences in higher education, research, technology and innovation, for bi-regional and intraregional associations which would provide academic and research programmes, mobility of academic staff and students, and the accreditation and recognition of studies, degrees and diplomas. The experience accumulated by European programmes such as Erasmus, Erasmus Mundus, Alfa, or the Framework Programmes for Science and Technology and Horizon 2020 are clear examples of success within Europe, which could be used as models to orient new programmes addressed to a bi-regional level.

The Strategic Association of Latin America and the Caribbean and the European Union, convened in the First Summit Meeting of Heads of State and Government, which gathered sixty countries and was held in Rio de Janeiro in 1999, declared higher education, science and technology as a priority. That was ratified in the following summits, with new and important decisions concerning the establishment of a Euro-Latin American Area of Knowledge and the JIRI (Joint Initiative for Research and Innovation). The conference of ministers of education of the two regions held in Paris in November 2000 emphasised the need to build up structures or frames of activity in order to achieve those objectives.

In June 2012 a significant number of higher education institutions of both regions met for the first time in Paris at the Institut des Amériques and held a seminar with the purpose of opening up a forum for reflection and debate on those issues. That first seminar was followed, in October 2012, by another seminar in Lima, at the "Colegio de Ingenieros del Perú", also sponsored by two organisations of Peruvian universities. Other international organisations soon 
joined this initiative, like the EU-LAC Foundation (established two years before) and its partners, i.e. the Global Foundation for Democracy and Development (FUNGLODE) of the Dominican Republic, the Lombardy region, the Institut des Amériques and the United Nations Economic Commission for Latin America and the Caribbean (ECLAC, or the acronym CEPAL for its initials in Spanish: "Comisión Económica para América Latina y el Caribe"). Those two first seminars in 2012 paved the way for the First Academic Summit, which took place in Santiago de Chile on 22nd-23rd January 2013, coinciding with the 7th Summit of European and Latin-American Heads of State and Government (or First CELAC-EU Summit of Heads of State and Government), following the example of parallel meetings organised a few years earlier by other sectors of civil society, such as NGOs, or the Business Summit (established in the Madrid Summit in 2000).

Those two meetings in 2012 were initially called by a group of institutions and academics from Chile and France (the Chilean Centro Latinoamericano para las Relaciones con Europa (CELARE) "Latin American Centre for the Relations with Europe", and the French Institut des Amériques) under the name of "Area for the Association of Latin America and the Caribbean and the European Union for Higher Education, Science, Technology and Innovation", but many other academics from numerous countries in the two regions soon joined the initiative, and as a consequence about 100 participants from more than 50 academic institutions from both regions contributed to each of those seminars.

The Academic Summit in Santiago de Chile in January 2013 was a great success. Relevant political authorities and academics of both regions took part in it: Benita Ferrero-Waldner, then President of the EU-LAC Foundation; José Ignacio Salafranca, President of the Euro-Latin American Parliamentary Assembly (EUROLAT); Simone Bonnafous, Director General of Higher Education of the French Government; Alfredo Moreno, Minister of Foreign Affairs of the Government of Chile; Alicia Bárcena, Executive Secretary of the Economic Commission for Latin America and the Caribbean (CEPAL); Leonel Fernández, President of FUNGLODE and former President of the Dominican Republic (now the current President of the EU-LAC Foundation), dozens of Presidents and Rectors of Latin American and European Universities and of course a huge 
number of academics interested in the educational cooperation between the two regions.

In total, some 650 academics representing 220 institutions from both regions participated in the debates and elaborated a Declaration which was presented to the Summit of Heads of State and Government held in Santiago on 26th-27th January, through a special meeting with the Ministers of Foreign Affairs and authorities of the European Union. The Declaration of the Summit of Heads of State and Government ratified again the importance of the development of joint actions in higher education, science, technology and innovation and took note of this first Academic Summit.

The Declaration of that first Academic Summit, with all the contributions made by academics, was published in a book comprising nearly 500 pages, which was an excellent testimony to the diversity and the joint efforts of so many institutions involved. I cannot even attempt to summarise all those papers of course; but the book is available on line (details are provided in the final bibliographical references).

One of the most relevant decisions taken in Santiago was also to give this initiative a more formal structure, in order to improve the organisation; so the Academic Permanent Forum was established, with an Executive Secretariat constituted by representatives of the Institut des Amériques and CELARE, and they started the elaboration of an Action Plan for the organisation of the Second Academic Summit.

During 2014 two other seminars were held, preparing the Second Academic Summit, to be held in Brussels in June 2015. The first seminar took place at the Institute of Latin American Studies (ISLA) of the National School of Political Studies and Public Administration (SNSPA) in Bucharest, on 26th-27th May 2014; and the second one at the University of Guadalajara, Mexico, on 25th-26th November. Both meetings were very well attended, with more participants than the previous seminars in Paris and Lima, and prepared the works for the Academic Summit in Brussels in June 2015; two books were published gathering the main papers and conclusions achieved in the debates. Before that Academic Summit another meeting was organised at the University of Alcalá (Spain) on 
13th-14th April 2015 and defined more closely the strategy for the organisation of the Summit.

During 2014 and 2015 the Academic Permanent Forum was getting stronger and reinforced its structure, due particularly to the incorporation to the Forum and the Seminars of more institutions and academics from both regions. In addition to the Executive Secretariat, four Permanent Reflection Groups were also created in the Guadalajara seminar, so as to coordinate the papers presented in seminars and Academic Summits, which reflect the four areas defined as priorities in the Santiago Academic Summit. Although some of the coordinators of those Groups have changed in the last two years, the current distribution of the Permanent Reflection Groups and their Chairs is as follows:

1. Higher Education, coordinated by Francisco Aldecoa (Complutense University, Madrid) and Alan Fairlie (Catholic University of Peru). This group works in the integration of the higher education systems in the two regions, including intra-regional Latin American and Caribbean convergence and the establishment of independent regional agencies for accreditation which develop models of recognition of credits and studies, among other measures, in order to foster mobility, doubles degrees, multidisciplinary programmes, e-learning, education and intercultural relations, higher education technical training, etc.

2. Science, Technology and Innovation, coordinated by Kajsa K. Ekroos (University of Helsinki) and Carlos Alberto Vigil (Cuba). The objectives of this group can be summarised in the institutionalisation of exchanges for research and the creation of a bi-regional agency of intellectual property, as well as the establishment of a bi-regional fund for the development of joint projects of research and innovation, mobility programmes for researchers and scientists, research and innovation for sustainable development, research infrastructures, etc.

3. Links with Society, coordinated by Celso Garrido (Metropolitan Autonomous University of Mexico) and Florence Pinot (ESCP Europe/CERALE, France). This group is mainly concerned with the development of proposals for a stronger interaction between universities and the productive sector, so as to promote research, $\mathrm{PhD}$ dissertations 
and projects funded by business and other firms, as well as entrepreneurship and innovation, with strong connections with society and industry.

4. Links with Public Policies, coordinated by Iordan Barbulescu (ISLA, National School of Political Studies and Public Administration, Romania) and Marco Moreno (Central University of Chile). This fourth group addresses the role our universities can play in the development of public policies in our respective countries and regions, such as the internationalisation of our institutions, or the implementation of policies of sustainability, or sustainable education, sexual and gender equality, or policies of healthcare and human rights related to the SDGs (Sustainable Development Goals) of the United Nations Agenda 2030.

The Brussels Academic Summit on 8th-9th June 2015 was very well attended, with more than 500 participants. A book of more than 600 pages was also published, collecting the main papers presented in Brussels. As it had happened in Santiago two years before, official support was given to the Forum and the Academic Summit by authorities in both regions: the Vice President of the European Parliament, in his capacity as Co-President of the Euro-Latin American Parliamentary Assembly, Mr Ramón Jáuregui; the European Commissioner for Science and Technology, Mr Carlos Moedas; the Secretary for Higher Education and Research of the Government of Ecuador, then having the pro-tempore Presidency of CELAC, Mr. René Ramírez; as well as other relevant personalities who had been present in Santiago, like the President of the EU-LAC Foundation, the Executive Secretary of CEPAL, etc.

The Declaration of this Academic Summit was presented to the CELAC-EU Summit Meeting of Heads of State and Government by the Presidents/Rectors of two universities: the University of Guadalajara Mexico and the National School of Political Studies and Public Administration of Bucharest, and it was significantly recognised by the official Declaration of the Summit, more particularly in chapter 9 of its Action Plan, together with other initiatives such as the JIRI and the Summit of Presidents of the Councils of Rectors of both regions. New steps have taken place since the Brussels Summit. On 1st February 2016 a meeting was convened in Lisbon, at the University Institute of Lisbon (ISCTE), 
for the constitution of a renovated Bi-Regional Academic Council (CAB) and a stronger Executive Secretariat, with the presence, in addition to the representatives of CELARE and the Institut des Amériques, of two other institutions: the University of Guadalajara and the National School of Political Studies and Public Administration of Bucharest, represented by Professor Iordan Barbulescu, President of its Senate. About 100 representatives also gathered for this Lisbon meeting in February 2016 and they approved the new Statutes of the Forum, thus formalising the five units of the Academic Permanent Forum, i.e. the Presidency, the Executive Secretariat, the Bi-Regional Academic Council, the four Permanent Reflection Groups, and the Bi-Regional Advisory Board. Detailed information about this can be found on our website (www.fap-alc-ue.com), but let me add that effort is continuously being made to maintain and reinforce the plurality and diversity of our two regions, as well as the high level of representation of higher education institutions in Europe and Latin America and the Caribbean.

The 3rd Academic Summit was due to take place in October 2017 in El Salvador, parallel as on previous occasions to the corresponding CELAC-EU Summit of Heads of State and Government, but this latter Summit has been postponed sine die, and we are now waiting for a final decision about dates and location. However, two semi-annual seminars were organised in 2016 in preparation for this Academic Summit; the first one on 21st-22nd June 2016, in Santo Domingo, Dominican Republic, organised jointly by the Academic Permanent Forum and the Dominican Government and higher education institutions in that country, such as the Autonomous University of Santo Domingo (UASD); the second seminar took place at the University of Stockholm, on 6th-7th October 2016, organised by the European Institute of International Studies, and sponsored by other organisations like the Swedish Ministry of Foreign Affairs, the Embassies of several Latin American countries in Stockholm, the governments of the Nordic countries, as well as of course EU-LAC Foundation, CELARE, and ISLA (Romania), among some others.

Another preparatory meeting of the Bi-Regional Academic Council was held on 5th-6th May 2017 at the University of Salamanca, and further discussed the agenda for the planned Academic Summit in El Salvador. Progress is now being 
made as work continues through the Permanent Reflection Groups. We expect to hold in 2018 the Third Academic Summit, where specific proposals will be discussed in order to be presented to the Ministers and the Heads of State and Government.

As I have tried to show, Latin American and Caribbean (LAC) education is one of the great global challenges we need to face, not only versus the Brexit and within the European Union, but also at an intra-regional level, in Latin America itself. As higher education is concerned, both in the UK and the EU, Latin America is still -and to a large extent- an almost terra incognita. Millions of LAC higher education students and staff, scientists and technologists are eager to participate in mobility programmes and in research collaboration with the EU and the UK.

The current aggressive US policy towards its southern neighbours, of which the Mexican wall is just one example, can surely help in making the EU (but also the UK) a haven for those LAC students and scholars who wish to contribute to a global world. Our students and staff in the EU would also benefit from those exchanges, and even, if I may say so, more easily than in the EU itself, as there are fewer language differences within the American subcontinent than in the EU, and that would certainly facilitate communication and academic exchanges.

If we have succeeded in our mobility programmes, in our accreditation and recognition of credits and diplomas within the EU, where twenty-four official languages coexist, why cannot we do so with Latin America, with fewer languages? It is our duty as academics involved in higher education, science, technology and innovation to work together in order to foster those alliances and to promote the necessary legal and structural changes in our institutions.

\section{REFERENCES}

- $\quad$ Ghymers, Christian and Patricio Leiva, eds. 2016. Construyendo el Espacio A cadémico Común de Educación Superior, Ciencia, Tecnología e Innovación para la A sociación Estratégica Birregional. Brussels: IRELAC. https://fapalcuecab2017.files.wordpress.com/2017/04/libro-bruselas.pdf 
- House of Commons Education Committee. 2017. Exiting the EU: Challenges and O pportunities for Higher Education. Ninth Report of Session 2016-17. HC 683. Published on 25 April 2017 by authority of the House of Commons. www.parliament.uk/education-committee

- Leiva, Patricio, ed. 2013. Hacia un Espacio Eurolatinoamericano y Caribeño para la Educación Superior, Ciencia, Tecnología e Innovación. Santiago de Chile: JC Sáez Editor. https://fapalcuecab2017.files.wordpress.com/2017/04/librosantiago.pdf

- $\quad$ Universities UK and UK International HE Unit. 2016. International H igher Education in Facts and Figures. June 2016. London: The UK HE International Unit. www.international.ac.uk 